\title{
An updated meta-analysis of 37 case-control studies on the association between NFKB1 -94ins/del ATTG promoter polymorphism and cancer susceptibility
}

\author{
Yi-Qiao Luo ${ }^{1, *}$, Duan Wang ${ }^{2, *}$, Teng Gong ${ }^{3}$ and Jiang Zhu ${ }^{4}$ \\ ${ }^{1}$ Department of Thoracic Oncology, West China Hospital/West China School of Medicine, Sichuan University, Chengdu, China \\ ${ }^{2}$ Department of Orthopaedics, West China School of Medicine, West China Hospital, Sichuan University, Chengdu, China \\ ${ }^{3}$ Sichuan Mianyang 404 Hospital, Mianyang, China \\ ${ }^{4}$ Department of Thoracic Oncology, West China Hospital, Sichuan University, Chengdu, China \\ * These authors have contributed equally to this work
}

Correspondence to: Jiang Zhu, email: zhujiang2866@163.com

Keywords: NFKB1; polymorphism; cancer; meta-analysis

Received: April 10,2016 Accepted: July 10, $2016 \quad$ Published: July 24, 2016

\section{ABSTRACT}

As a cell survival signal, nuclear factor-kappa B (NFKB) is associated with the pathogenesis of numerous malignancies. According to several studies, NFKB1 -94ins/ del ATTG promoter polymorphism is associated with the risk of different malignancies, but the results were not consistent. Therefore, we performed an updated metaanalysis based on 37 case-control studies from 33 articles $(16,271$ cases and 22,781 controls) to clarify the relationship. The odds ratio (OR) and $95 \%$ confidence interval (CI) were used to determine the strength of the association. We found that the NFKB1 -94ins/del ATTG promoter polymorphism was significantly associated with increased susceptibility to cancer in the recessive (II vs. ID+DD, OR $=1.140,95 \%$ CI $=1.029$ $1.263, p=0.012$ ), homozygote (II vs. DD, OR $=1.259,95 \% \mathrm{CI}=1.068-1.485, p=$ 0.006 ), and allele ( $I$ vs. $D, O R=1.109,95 \% C I=1.025-1.199, p=0.010)$ genetic models. The subgroup analysis for ethnicity found that the NFKB1 -94ins/del ATTG promoter polymorphism was significantly associated with an increased susceptibility to cancer in Asians and with a decreased susceptibility in Caucasians. The stratified analyses revealed significant associations between the polymorphism and increased susceptibility to ovarian cancer, oral squamous cell carcinoma, and nasopharyngeal carcinoma.

\section{INTRODUCTION}

Cancer is the result of complex interactions between inherited and environmental factors, which threatens people worldwide due to high morbidity and mortality [1]. Although the aetiology of this disease remains unclear, genetic susceptibility is one known explanation for the inter-individual variation in cancer risk [2]. Many researchers have been studying the aetiology of oncogenesis, and have identified the relationship between genetic polymorphism and cancer risk, especially for the NFKB1 -94ins/del ATTG promoter polymorphism.

$N F K B$ is responsible for regulating the expression of many genes for immune response, cell adhesion, differentiation, proliferation, angiogenesis and apoptosis
[3]. $N F K B$ was first identified by Sen and Baltimore in 1986 [4]. As a transcription factor, $N F K B$ binds to a 10 bp DNA element in kappa immunoglobulin light-chain enhancer in B cells [5]. The NFKB family consists of $\mathrm{p} 50 /$ p105, p65/Rel A, c-Rel, Rel B, and p52/p100. Among them, the major form of $N F K B$ is a heterodimer of the p50/p105 and p65/Rel A subunits that are encoded by the $N F K B 1$ and $N F K B 2$ genes, respectively [49]. The human $N F K B 1$ gene, located on chromosome $4 \mathrm{q} 24$, encodes a $50 \mathrm{kDa}$ DNA-binding protein that can act as a master regulator of inflammation and cancer development $[6,7]$.

A common insertion/deletion polymorphism in the promoter region of the $N F K B 1$ gene elicits a regulatory effect on the $N F K B 1$ gene [8] and an increasing number of studies have assessed the association between the NFKBI 
Table 1: Characteristics of studies included in the meta-analysis

\begin{tabular}{|c|c|c|c|c|c|c|c|c|c|c|c|c|c|c|}
\hline Author & Year & \begin{tabular}{|l|} 
Ethnicity \\
\end{tabular} & Country & Cases & Control & Method & Cancer type & Case & & & Con & trol & & HWE \\
\hline & & & & & & & & II & ID & DD & II & ID & DD & \\
\hline Lin & 2006 & Asian & China & 212 & 201 & PCR & OSCC & 59 & 103 & 50 & 43 & 100 & 58 & 0.993 \\
\hline Riemann & 2006 & Caucasian & Germany & 139 & 307 & PCR-RFLP & CRC & 54 & 58 & 27 & 118 & 141 & 48 & 0.586 \\
\hline Riemann & 2006 & Caucasian & Germany & 72 & 307 & PCR-RFLP & B cell CLL & 18 & 41 & 13 & 118 & 141 & 48 & 0.586 \\
\hline Riemann & 2006 & Caucasian & Germany & 140 & 307 & PCR-RFLP & RCC & 47 & 76 & 17 & 118 & 141 & 48 & 0.586 \\
\hline Riemann & 2007 & Caucasian & Germany & 242 & 307 & PCR-RFLP & $\mathrm{BC}$ & 88 & 124 & 30 & 118 & 141 & 48 & 0.586 \\
\hline Lo & 2009 & Asian & China & 182 & 116 & PCR & $\mathrm{GC}$ & 62 & 89 & 31 & 20 & 62 & 34 & 0.361 \\
\hline $\mathrm{He}$ & 2009 & Asian & China & 202 & 404 & PCR-RFLP & $\mathrm{HCC}$ & 83 & 84 & 35 & 97 & 183 & 124 & 0.07 \\
\hline Zhang & 2009 & Asian & China & 117 & 143 & PCR-PAGE & PC & 46 & 57 & 14 & 44 & 68 & 31 & 0.624 \\
\hline Zhou & 2009 & Asian & China & 163 & 203 & PCR-RFLP & NPC & 74 & 67 & 22 & 71 & 90 & 42 & 0.177 \\
\hline Zhou & 2010 & Asian & China & 233 & 365 & PCR-PAGE & $\mathrm{CSCC}$ & 108 & 105 & 20 & 135 & 166 & 64 & 0.297 \\
\hline Andersen & 2010 & Caucasian & Denmark & 378 & 756 & TaqMan & CRC & 121 & 195 & 62 & 307 & 347 & 102 & 0.801 \\
\hline Tang & 2010 & Asian & China & 207 & 228 & PCR-PAGE & $\mathrm{BC}$ & 89 & 92 & 26 & 74 & 108 & 46 & 0.565 \\
\hline Song & 2011 & Asian & China & 1001 & 1005 & PCR-RFLP & CRC & 363 & 500 & 138 & 297 & 522 & 186 & 0.102 \\
\hline Fan & 2011 & Asian & China & 179 & 223 & PCR-CE & $\mathrm{OC}$ & 78 & 84 & 17 & 76 & 103 & 44 & 0.396 \\
\hline Vangsted & 2012 & Caucasian & Denmark & 348 & 1700 & Taqman & MM & 110 & 163 & 55 & 665 & 778 & 253 & 0.303 \\
\hline Ungerback & 2012 & Caucasian & Sweden & 344 & 622 & TaqMan & CRC & 114 & 187 & 43 & 256 & 270 & 96 & 0.079 \\
\hline Liu & 2012 & Asian & China & 906 & 906 & PCR & NPC & 269 & 467 & 170 & 280 & 433 & 193 & 0.289 \\
\hline Lin & 2012 & Asian & China & 462 & 520 & TaqMan & OSCC & 116 & 246 & 100 & 81 & 271 & 168 & 0.099 \\
\hline Kopp & 2013 & Caucasian & Denmark & 334 & 334 & TaqMan & PC & 128 & 152 & 54 & 109 & 161 & 64 & 0.741 \\
\hline Huo & 2013 & Asian & China & 187 & 221 & PCR & $\mathrm{OC}$ & 83 & 82 & 22 & 71 & 103 & 47 & 0.399 \\
\hline Cheng & 2013 & Asian & China & 135 & 520 & RT-PCR & $\mathrm{HCC}$ & 42 & 64 & 29 & 81 & 271 & 168 & 0.099 \\
\hline $\mathrm{Li}$ & 2013 & Asian & China & 609 & 640 & TaqMan & $\mathrm{BC}$ & 189 & 269 & 151 & 223 & 324 & 93 & 0.156 \\
\hline Oltulu & 2014 & Caucasian & Turkey & 95 & 99 & PCR-RFLP & NSCLC & 35 & 44 & 16 & 46 & 47 & 6 & 0.18 \\
\hline Hua & 2014 & Asian & China & 401 & 433 & HарМар & GC & 92 & 182 & 127 & 120 & 230 & 83 & 0.144 \\
\hline Zhang & 2014 & Asian & China & 624 & 1606 & PCR & $\mathrm{HCC}$ & 205 & 312 & 107 & 542 & 790 & 274 & 0.63 \\
\hline Liu & 2015 & Asian & China & 1590 & 1979 & HapMap & NPC & 552 & 769 & 269 & 610 & 950 & 419 & 0.169 \\
\hline Wang & 2015 & Asian & China & 421 & 425 & PCR-RFLP & NSCLC & 113 & 219 & 89 & 89 & 205 & 131 & 0.595 \\
\hline $\mathrm{Lu}$ & 2015 & Asian & China & 687 & 687 & PCR-RFLP & $\mathrm{OC}$ & 115 & 351 & 221 & 95 & 339 & 253 & 0.271 \\
\hline Kopp & 2015 & Caucasian & Denmark & 915 & 1719 & KASP & CRC & 320 & 449 & 146 & 679 & 787 & 253 & 0.311 \\
\hline Chen & 2015 & Asian & China & 410 & 442 & PCR & $\mathrm{OC}$ & 120 & 195 & 95 & 85 & 235 & 122 & 0.136 \\
\hline $\mathrm{Li}$ & 2015 & Asian & China & 730 & 780 & TaqMan & $\mathrm{BC}$ & 227 & 316 & 187 & 261 & 395 & 124 & 0.208 \\
\hline $\mathrm{Li}$ & 2015 & Asian & China & 1216 & 1588 & TaqMan & $\mathrm{RCC}$ & 451 & 577 & 188 & 582 & 781 & 225 & 0.152 \\
\hline $\mathrm{Li}$ & 2015 & Asian & China & 820 & 945 & TaqMan & PC & 299 & 377 & 144 & 347 & 462 & 136 & 0.371 \\
\hline Wang & 2015 & Asian & China & 352 & 459 & PCR & PTC & 106 & 186 & 60 & 171 & 209 & 79 & 0.273 \\
\hline $\mathrm{Li}$ & 2015 & Asian & China & 220 & 222 & PCR-RFLP & Osteosarcoma & 60 & 114 & 46 & 50 & 106 & 66 & 0.55 \\
\hline Han & 2015 & Asian & China & 936 & 936 & PCR-RFLP & PC & 63 & 339 & 534 & 38 & 331 & 567 & 0.23 \\
\hline Rybka & 2016 & Caucasian & Poland & 62 & 126 & PCR & AML & 25 & 30 & 7 & 43 & 69 & 14 & 0.079 \\
\hline
\end{tabular}

PTC papillary thyroid carcinoma, CRC colorectal cancer, BC, bladder cancer, OC ovarian cancer, PC prostate cancer, HCC hepatocellular carcinoma, GC gastric cancer, OSCC oral squamous cell carcinoma, NSCLC none small cell lung cancer, NPC nasopharyngeal carcinoma, RCC renal cell carcinoma, MM multiple myeloma, AML acute myeloid leukaemia 
-94ins/del ATTG promoter polymorphism and cancer risk [9-11]. However, some researchers could not replicate this association. Previous meta-analysis [45-48] focused on the relationship between the NFKB1-94ins/del ATTG promoter polymorphism and cancer, but the results were inconsistent. Since then, several other studies [36-44] performed on large case and control groups have assessed the relationships between the NFKB1 -94ins/del ATTG promoter polymorphism and susceptibility to a variety of cancers. Therefore, to better understand the precise relationships, we performed a comprehensive updated meta-analysis with increased statistical power.

\section{RESULTS}

\section{Characteristics of eligible studies}

Our electronic database search resulted in 202 articles and 2 articles were available manually, we scanned all of the abstracts, and there were 45 articles that conformed to the inclusion criteria, we excluded 9 articles [52-60] that did not conform to HWE, 2 studies $[61,62]$ were excluded as they were duplications of previous publications and 1 study [63] did not have completely extractable data. Thus, we included 33 independent records [14-44, 50-51]. Riemann et al [15] was treated as three independent case groups because three cancer types were studied along with a control sample. Li et al [39] conducted their research in three types of urinary cancer (renal cancer, bladder cancer and prostate cancer), so we treated the data as three separate comparisons. Finally, a total of 37 separate studies involving 16,271 cases and 22,781 controls were available for our updated metaanalysis. Figure 1 describes the process for the study. Characteristics of the eligible studies are summarized in Table 1. Among them, 26 studies were performed in Asian populations and 11 studies in Caucasian populations. In total, this meta-analysis included 5 studies on colorectal cancer studies, 4 on bladder cancer studies, 4 on ovarian cancer studies, 4 on prostate cancer studies, 3 on hepatocellular carcinoma studies, 3 on nasopharyngeal carcinoma studies, 2 on gastric cancer studies, 2 on oral squamous cell carcinoma studies, 2 on non-small cell lung cancer studies, 2 on renal cell cancer studies and 5 on other cancers. All cases were clinically pathologically confirmed.

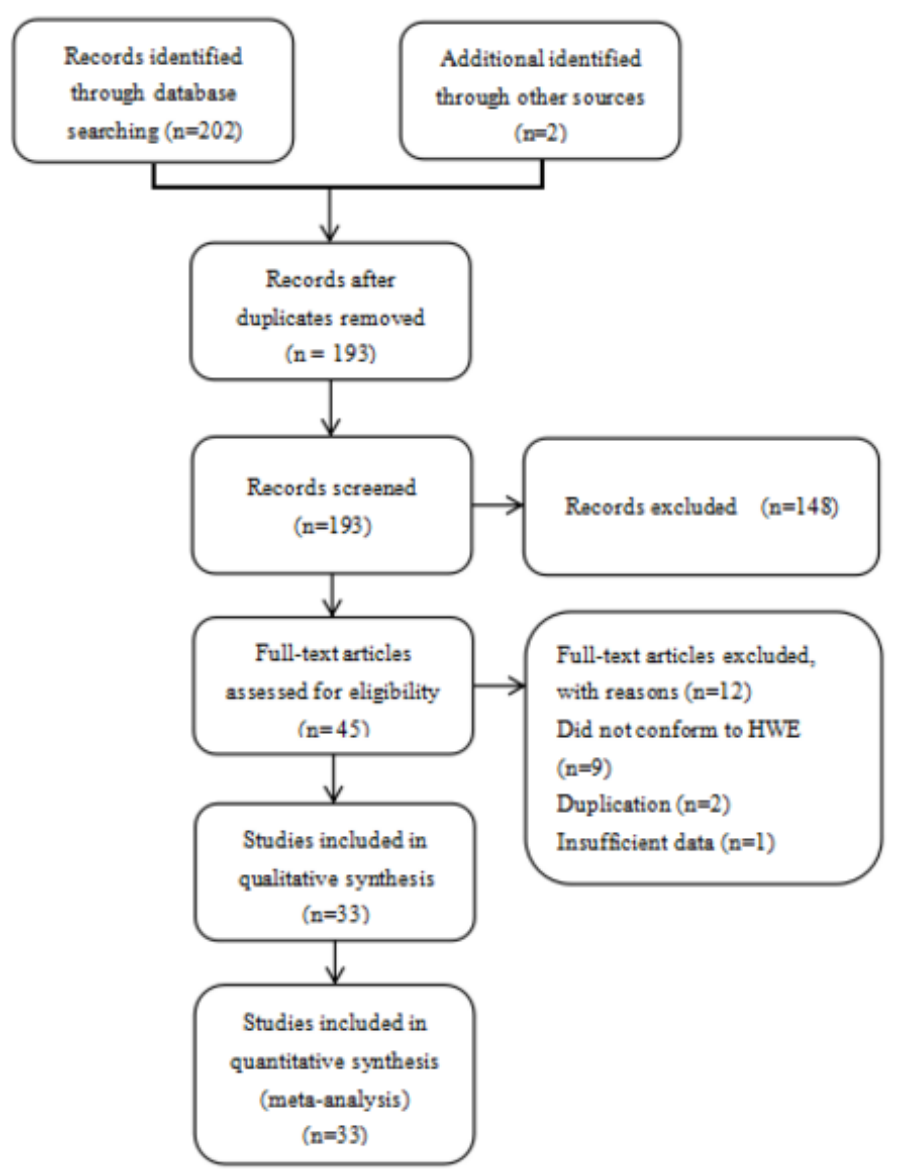

Figure 1: Flow chart of the process for study identification and selection. 
Table 2: Associations between the NFKB1 -94ins/del ATTG promoter polymorphism and cancer risk

\begin{tabular}{|c|c|c|c|c|c|c|c|c|c|c|c|c|}
\hline & & & II+ID vs. DD & & $\begin{array}{|lr|}\text { II } & v s . \\
\text { ID+DD } & \\
\end{array}$ & & II vs. DD & & ID vs. DD & & I vs. D & \\
\hline Variables & $\mathrm{N}^{\mathrm{a}}$ & Case/Control & OR $(95 \%$ CI $)$ & $I^{2} \%$ & $\begin{array}{l}\text { OR } \\
\text { CI })\end{array}$ & $I^{2} \%$ & OR $(95 \% \mathrm{CI})$ & $I^{2} \%$ & OR $(95 \% \mathrm{CI})$ & $I^{2} \%$ & $\begin{array}{ll}\text { OR } & (95 \% \\
\mathrm{CI}) & \end{array}$ & $\mathrm{I}^{2} \%$ \\
\hline Overall & 37 & $16271 / 22781$ & & 83.2 & $\begin{array}{l}1.140(1.029- \\
1.263) \mathrm{b}\end{array}$ & 78 & $\begin{array}{l}1.259(1.068- \\
1.485) \mathrm{b}\end{array}$ & 84.0 & $\begin{array}{l}8(0.997- \\
33)^{\mathrm{b}}\end{array}$ & 72.6 & $\begin{array}{l}1.109(1.025- \\
1.199) \mathrm{b}\end{array}$ & 84.2 \\
\hline \multicolumn{13}{|l|}{ Ethnicity } \\
\hline Asian & 26 & $13202 / 16197$ & \begin{tabular}{|l|}
$.223(1.031-$ \\
$1.451) \mathrm{b}$
\end{tabular} & 87.3 & $\begin{array}{l}1.280(1.142- \\
1.435) \mathrm{b}\end{array}$ & 76.3 & $1.788) \mathrm{b}$ & 86.6 & $\begin{array}{l}.151(0.999- \\
1.327)^{\mathrm{b}} \\
\end{array}$ & 78.8 & \begin{tabular}{|l|}
$1.199(1.092-$ \\
$1.317) \mathrm{b}$ \\
\end{tabular} & 86.0 \\
\hline Caucasian & 11 & $3069 / 6584$ & \begin{tabular}{|l|}
$0.957(0.847-$ \\
$1.081)$
\end{tabular} & 27.5 & \begin{tabular}{|l|}
$0.824(0.752-$ \\
$0.903)$
\end{tabular} & 39.9 & & 36.2 & & 24.8 & \begin{tabular}{|l|}
$0.899(0.844-$ \\
$0.958)$
\end{tabular} & 36.1 \\
\hline \multicolumn{13}{|l|}{ Cancer types } \\
\hline Colorectal cancer & 5 & 2777/4409 & & 68.3 & $\begin{array}{l}0.890(0.675- \\
1.173)^{\mathrm{b}}\end{array}$ & 85 & & 81.4 & & 49.9 & $\begin{array}{l}0.946(0.785- \\
1.140)^{\mathrm{b}}\end{array}$ & 84.4 \\
\hline Bladder cancer & 4 & $1788 / 1955$ & & 90.3 & \begin{tabular}{|l|}
$0.983(0.782-$ \\
$1.236)^{\mathrm{b}}$
\end{tabular} & 60.8 & \begin{tabular}{|l|}
$0.893(0.510-$ \\
$1.564)^{\mathrm{b}}$
\end{tabular} & 87.1 & & 86.3 & \begin{tabular}{|l|}
$0.948(0.733-$ \\
$1.227)^{\mathrm{b}}$
\end{tabular} & 85.7 \\
\hline Ovarian cancer & 4 & $1463 / 1573$ & $\begin{array}{l}1.481(1.128- \\
1.943) \mathrm{b}\end{array}$ & 51.6 & \begin{tabular}{|l|}
$1.503(1.265-$ \\
$1.786)$
\end{tabular} & 0 & $\begin{array}{l}1.761(1.420- \\
2.184)\end{array}$ & 39.8 & $\begin{array}{l}1.246(1.048- \\
1.482)\end{array}$ & 37.9 & \begin{tabular}{|l|}
$1.308(1.181-$ \\
$1.449)$
\end{tabular} & 38.5 \\
\hline Prostate cancer & 4 & $2207 / 2358$ & \begin{tabular}{|l|}
$1.099(0.753-$ \\
$1.604)^{\mathrm{b}}$ \\
\end{tabular} & 82.0 & \begin{tabular}{|l|}
$1.266(0.978-$ \\
$1.639)^{\mathrm{b}}$
\end{tabular} & 57.6 & \begin{tabular}{|l|}
$1.382(0.864-$ \\
$2.210)^{\mathrm{b}}$ \\
\end{tabular} & 78.2 & \begin{tabular}{|l|}
$1.039(0.797-$ \\
$1.355)^{\mathrm{b}}$ \\
\end{tabular} & 59.1 & \begin{tabular}{|l|}
$1.138(0.955-$ \\
$1.357)^{\mathrm{b}}$ \\
\end{tabular} & 69.5 \\
\hline Gastric cancer & 2 & $583 / 549$ & \begin{tabular}{|l|}
$0.997(0.260-$ \\
$3.826)^{\mathrm{b}}$ \\
\end{tabular} & 94.3 & $\begin{array}{l}1.353(0.434- \\
4.221)^{\mathrm{b}} \\
\end{array}$ & 91.8 & \begin{tabular}{|l|}
$1.275(0.195-$ \\
$8.331)^{\mathrm{b}}$
\end{tabular} & 95.5 & $\begin{array}{l}0.879(0.295- \\
2.613)^{\mathrm{b}} \\
\end{array}$ & 90.4 & \begin{tabular}{|l|}
$1.116(0.447-$ \\
$2.784)^{\mathrm{b}}$
\end{tabular} & 95.6 \\
\hline $\begin{array}{l}\text { Oral squamous } \\
\text { cell carcinoma }\end{array}$ & 2 & $674 / 721$ & $\begin{array}{l}1.593(1.253- \\
2.026) \\
\end{array}$ & 3.9 & \begin{tabular}{|l|}
$1.674(1.292-$ \\
$2.169)$ \\
\end{tabular} & 0 & \begin{tabular}{|l|}
$2.104(1.545-$ \\
$2.867)$
\end{tabular} & 33.0 & $\begin{array}{l}1.420(1.102- \\
1.829) \\
\end{array}$ & 0 & \begin{tabular}{|l|}
$1.427(1.229-$ \\
$1.657)$ \\
\end{tabular} & 6.9 \\
\hline $\begin{array}{l}\text { None small cell } \\
\text { lung cancer }\end{array}$ & 2 & $516 / 524$ & \begin{tabular}{|l|}
$0.779(0.155-$ \\
$3.921)^{\mathrm{b}}$ \\
\end{tabular} & 89.8 & $\begin{array}{l}1.005(0.497- \\
2.033)^{\mathrm{b}}\end{array}$ & 78.6 & \begin{tabular}{|l|}
$0.778(0.124-$ \\
$4.904)^{\mathrm{b}}$
\end{tabular} & 91.0 & $\begin{array}{l}0.806(0.187- \\
3.478)^{\mathrm{b}}\end{array}$ & 86.6 & \begin{tabular}{|l|}
$0.955(0.453-$ \\
$2.017)^{\mathrm{b}}$
\end{tabular} & 90.5 \\
\hline $\begin{array}{l}\text { Hepatocellular } \\
\text { carcinoma }\end{array}$ & 3 & $961 / 2530$ & $\begin{array}{l}1.503(0.907- \\
2.492)^{\mathrm{b}}\end{array}$ & 82.4 & $\begin{array}{l}1.699(0.873- \\
3.307)^{\mathrm{b}}\end{array}$ & 92.2 & $\begin{array}{l}2.022(0.861- \\
4.746)^{\mathrm{b}}\end{array}$ & 91.8 & $\begin{array}{l}1.179(0.962- \\
1.445)\end{array}$ & 44.9 & \begin{tabular}{|l|}
$1.442(0.916-$ \\
$2.271)^{\mathrm{b}}$
\end{tabular} & 92.8 \\
\hline $\begin{array}{l}\text { Nasopharyngeal } \\
\text { Carcinoma }\end{array}$ & 3 & 2659/3088 & \begin{tabular}{|l|}
$1.200(0.883-$ \\
$1.631)^{\mathrm{b}}$
\end{tabular} & 73.7 & $\begin{array}{l}1.146(0.918- \\
1.431)^{\mathrm{b}}\end{array}$ & 65.4 & $\begin{array}{l}1.339(1.040- \\
1.724) \mathrm{b} \\
\end{array}$ & 52.0 & $\begin{array}{l}1.257(1.092- \\
1.447) \\
\end{array}$ & 0 & $\begin{array}{l}1.158(1.002- \\
1.337) \mathrm{b} \\
\end{array}$ & 63.2 \\
\hline Rental cell cancer & 2 & $1356 / 1895$ & $\begin{array}{l}0.947(0.564- \\
1.591)^{\mathrm{b}}\end{array}$ & 65.8 & $\begin{array}{l}0.991(0.857- \\
1.146)\end{array}$ & 1.9 & \begin{tabular}{|l|}
$0.948(0.764-$ \\
$1.176)$
\end{tabular} & 0 & $\begin{array}{l}1.071(0.644- \\
1.780)^{\mathrm{b}}\end{array}$ & 61.8 & \begin{tabular}{|l|}
$0.981(0.886-$ \\
$1.086)$
\end{tabular} & 0 \\
\hline Other cancers & 6 & $1287 / 3179$ & \begin{tabular}{|l|}
$1.174(0.851-$ \\
$1.619)^{\mathrm{b}}$
\end{tabular} & 61.5 & $\begin{array}{l}0.952(0.704- \\
1.286)^{\mathrm{b}}\end{array}$ & 73.1 & \begin{tabular}{|l|}
$1.105(0.705-$ \\
$1.733)^{\mathrm{b}}$
\end{tabular} & 75.0 & $\begin{array}{l}1.218(1.003- \\
1.480)\end{array}$ & 24.7 & \begin{tabular}{|l|}
$1.029(0.822-$ \\
$1.288)^{\mathrm{b}}$
\end{tabular} & 78.2 \\
\hline
\end{tabular}

The bold values indicate that the association is significant

${ }^{a}$ Number of comparisons

${ }^{\mathrm{b}}$ Random-effect model

\section{Meta-analysis of the overall population}

The main meta-analysis results of the association between the NFKB1 -94ins/del ATTG promoter polymorphism and cancer risk are shown in Table 2. All $P$ values displayed obvious heterogeneity between the selected research studies under all five genetic models of the updated meta-analysis. Thus, the random-effect model was used. We found that the NFKB1 -94ins/del ATTG promoter polymorphism was significantly increased cancer risk in homozygote (II vs. DD, OR $=1.259,95 \%$ $\mathrm{CI}=1.068-1.485)$, recessive (II vs. ID+DD, $\mathrm{OR}=1.140$, $95 \% \mathrm{CI}=1.029-1.263)$ and allele (I vs. $\mathrm{D}, \mathrm{OR}=1.109$, $95 \% \mathrm{CI}=1.025-1.199)$ genetic models. However, the association was not found in II+ID vs. DD (OR $=1.139$, $95 \% \mathrm{CI}=0.994-1.305)$ and ID $v s . \mathrm{DD}(\mathrm{OR}=1.118,95 \%$ $\mathrm{CI}=0.997-1.253$ ). (Figure 2)

\section{Subgroup analyses}

The subgroup analysis for ethnicity revealed significant increases in susceptibility for cancer risk in the four models among Asians (II+ID vs. DD, OR = $1.223,95 \% \mathrm{CI}=1.031-1.451$; II $v s$. ID $+\mathrm{DD}, \mathrm{OR}=1.280$, $95 \% \mathrm{CI}=1.142-1.435 ; \mathrm{II} v s . \mathrm{DD}, \mathrm{OR}=1.463,95 \% \mathrm{CI}=$ $1.196-1.788$; I vs. $\mathrm{D}, \mathrm{OR}=1.199,95 \% \mathrm{CI}=1.092-1.317$ ) and decreases in susceptibility in three models among Caucasians (II vs. ID+DD, OR $=0.824,95 \% \mathrm{CI}=0.752$ 0.903; II vs. DD, OR $=0.855,95 \% \mathrm{CI}=0.748-0.979$; I vs. $\mathrm{D}, \mathrm{OR}=0.899,95 \% \mathrm{CI}=0.844-0.958$ ). (Figure 3, Table 2). The stratified analyses revealed a significant association between the polymorphism and ovarian cancer (II+ID vs. DD, OR $=1.481,95 \% \mathrm{CI}=1.128-1.943$; II vs. $\mathrm{ID}+\mathrm{DD}, \mathrm{OR}=1.503,95 \% \mathrm{CI}=1.265-1.786 ; \mathrm{II} v s . \mathrm{DD}$, $\mathrm{OR}=1.761,95 \% \mathrm{CI}=1.420-2.184 ;$ ID $v s . \mathrm{DD}, \mathrm{OR}=$ $1.246,95 \% \mathrm{CI}=1.048-1.482 ; \mathrm{I} v s . \mathrm{D}, \mathrm{OR}=1.308,95 \%$ $\mathrm{CI}=1.181-1.449)$, oral squamous cell carcinoma (II+ID $v s . \mathrm{DD}, \mathrm{OR}=1.593,95 \% \mathrm{CI}=1.253-2.026$; II $v s$. ID+DD, $\mathrm{OR}=1.674,95 \% \mathrm{CI}=1.292-2.169 ;$ II vs. DD, OR $=$ $2.104,95 \% \mathrm{CI}=1.545-2.867$; ID vs. $\mathrm{DD}, \mathrm{OR}=1.420$, 
$95 \% \mathrm{CI}=1.102-1.829 ; \mathrm{I}$ vs. $\mathrm{D}, \mathrm{OR}=1.427,95 \% \mathrm{CI}=$ 1.229-1.657) and nasopharyngeal carcinoma ( II vs. DD, $\mathrm{OR}=1.339,95 \% \mathrm{CI}=1.040-1.724 ; \mathrm{ID} v s . \mathrm{DD}, \mathrm{OR}=$ $1.257,95 \% \mathrm{CI}=1.092-1.447$; I vs. $\mathrm{D}, \mathrm{OR}=1.158,95 \%$ $\mathrm{CI}=1.002-1.337)$ in the models. However, we did not find associations in hepatocellular carcinoma, colorectal cancer, bladder cancer, prostate cancer, non-small cell lung cancer and renal cell cancer (Table 2).

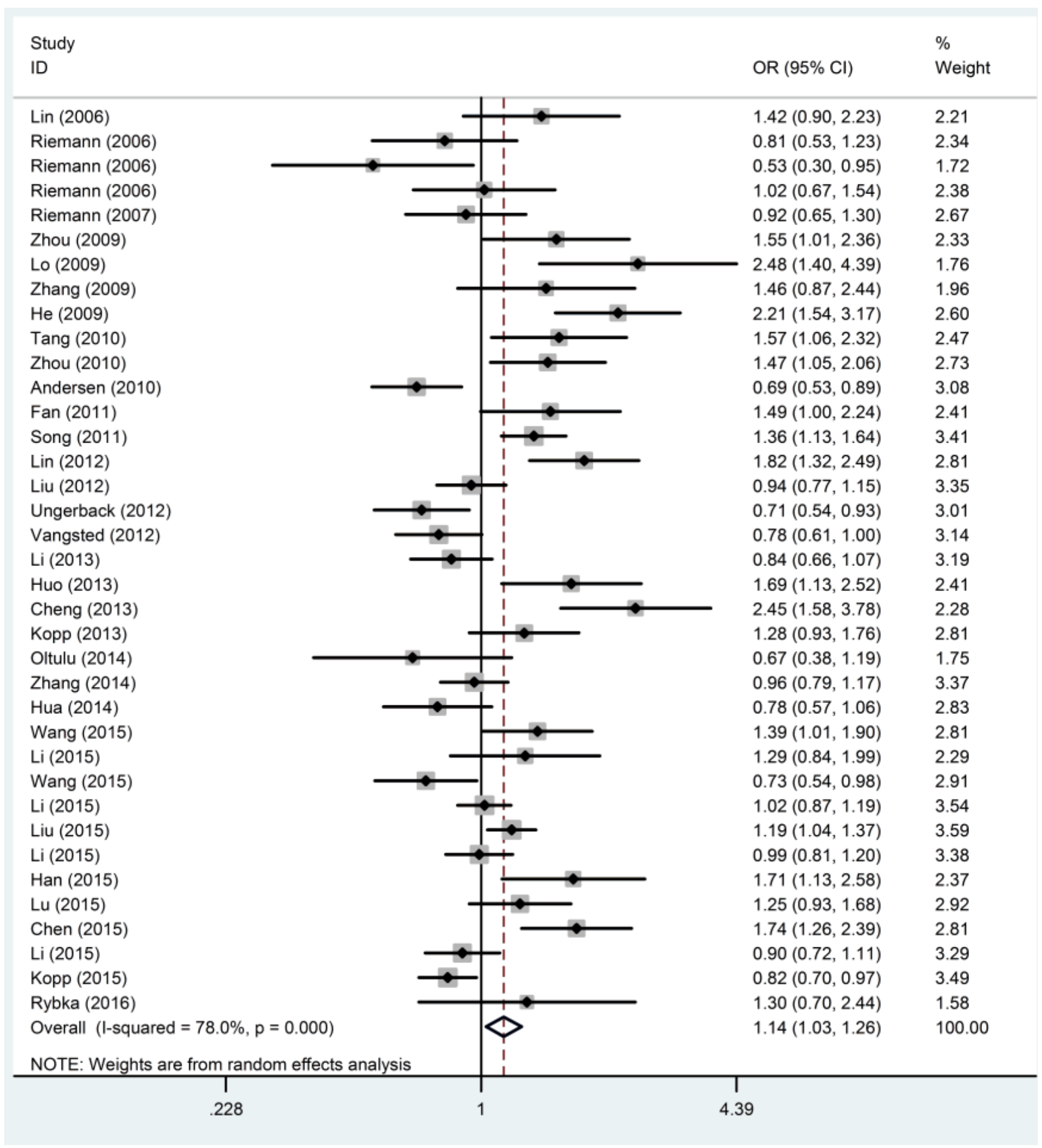

Figure 2: Forest plots of ORs with 95\% CI for the NFKB1 -94ins/del ATTG promoter polymorphism and risk of cancer in the overall population (II vs. ID + DD). 


\section{Publication bias}

The publication bias analysis was performed by Begg's funnel plot and Egger's test. The shape of the Begg's funnel plots seemed symmetrical (Figure 4) and Egger's test suggested no evidence of significant publication bias $(p=0.161$ for the dominant model, $p=0.056$ for the recessive model, $p=0.092$ for the homozygote model, $p=0.239$ for the heterozygote model, and $p=0.117$ for the allele model) in this updated metaanalysis.

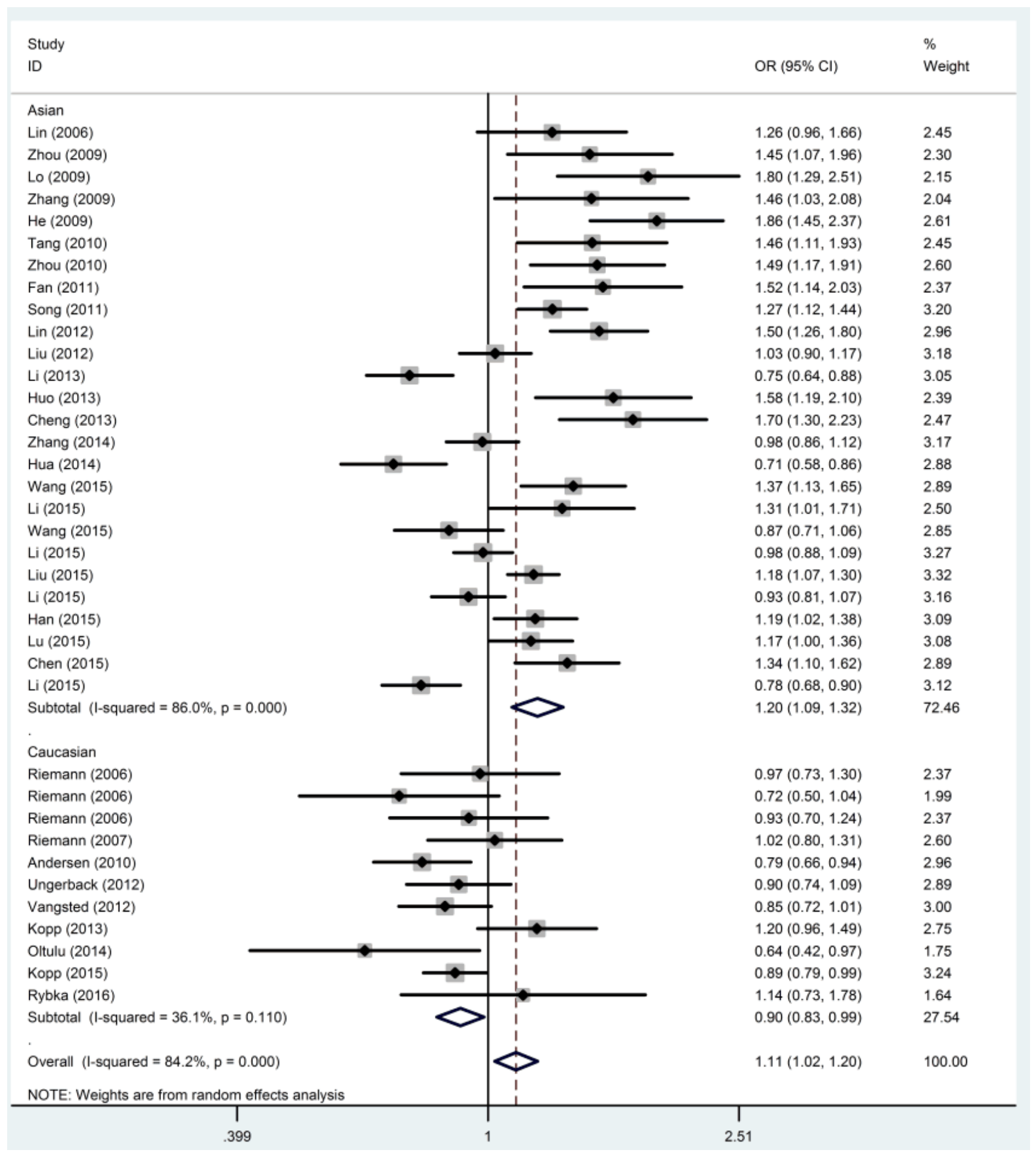

Figure 3: Forest plots of ORs with $95 \%$ CI for the NFKB1 -94ins/del ATTG promoter polymorphism and risk of cancer in ethnicity (I vs. D). 


\section{Sensitivity analysis}

The sensitivity analysis was performed by the sequential omission of individual studies. After excluding each study sequentially, we obtained statistically similar results (data not shown), suggesting that the data of our meta-analysis are relatively stable and credible. In addition, the random-effects model was compared with the fixed-effects model, and the statistically similar results were obtained in all genetic models.

\section{DISCUSSION}

In recent years, several investigators reported the association between the NFKB1 -94ins/del ATTG promoter polymorphism and risk of cancers [14-35] such as bladder, ovarian, prostate, gastric and breast cancers as well as non-small cell lung, hepatocellular and nasopharyngeal carcinomas, but the results are inconclusive. Previous meta-analyses [45-48] had the drawback of a limited number of studies included and small sample sizes, or studies that were not in HWE were not excluded, which may affect the validity of the conclusions. Many relevant case-control studies were published recently [36-44], including more ethnicities and cancer types. However, the results of these articles were not consistent in previous meta-analyses. To provide a more comprehensive conclusion, we expanded the sample size to more than double through the addition of new studies that were published since the previous metaanalyses.

We performed a meta-analysis of 37 case-control studies from 33 articles $(16,271$ cases and 22,781 controls) to clarify the relationship between the NFKB1 -94ins/del ATTG promoter polymorphism and cancer susceptibility. We found that the NFKB1 -94ins/del ATTG promoter polymorphism was significantly associated with increased risk of cancer; this result was different than a previous meta-analysis [48], which reported that there was no association between the NFKB1 -94ins/del ATTG promoter polymorphism and cancer risk. The reasons for this difference could be explained as follows: 1) we included 37 case-control studies, versus only 11 studies ( 2,743 cases and 2,195 controls) in the previous metaanalysis, and therefore, the results of this meta-analysis were more credible; and 2) there may be some factors among the study populations that could influence the results, including age, gender, life style, and environment. In addition, when compared with the meta-analysis by Wenyuan Duan [45], although we reached the same conclusion in the terms of overall population, our analysis has some advantages: 1) we excluded articles that do not conform to HWE, whereas the previous meta-analyses did not; and 2) we included 37 studies, whereas previous meta-analyses included just 25 studies, which could lead

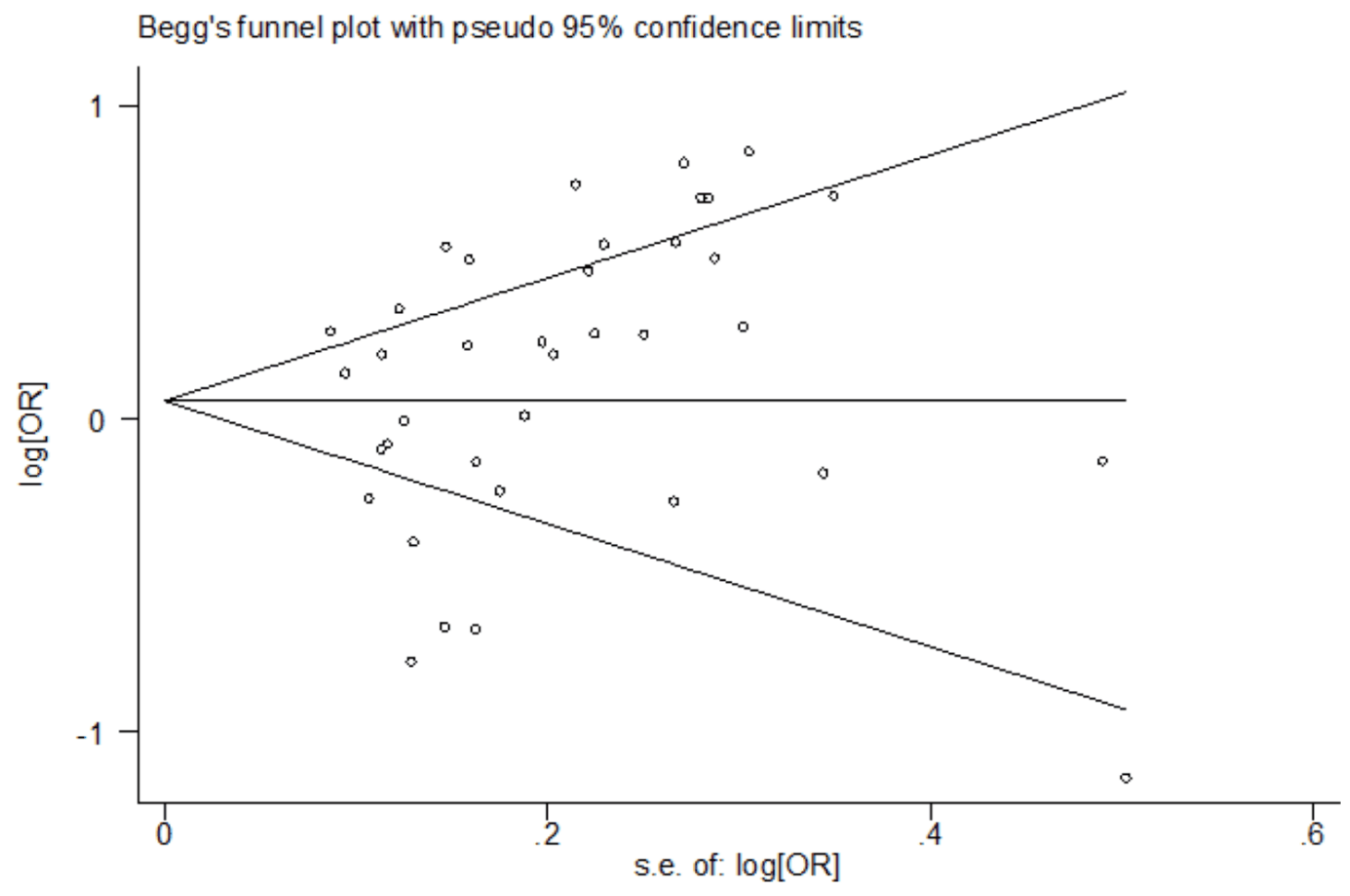

Figure 4: Begg's funnel plot of the association between the NFKB1 -94ins/del ATTG promoter polymorphism and risk of cancer (II + ID vs. DD). 
to a lack of statistical power and reliability. However, we must be careful in explaining the results due to the moderate heterogeneity. To investigate the origin of the heterogeneity, we conducted a stratification analysis based on ethnicity and cancer type. In the subgroup analysis of ethnicity, we found a significant association of the NFKB1 -94ins/del ATTG promoter polymorphism with increased and decreased cancer risk in Asian and Caucasian populations, respectively. Surprisingly, the results were different from the result shown by a previous metaanalysis [45], which conducted that the NFKB1-94ins/del ATTG promoter polymorphism was associated with risk in Asians but not in Caucasians population. The results may be explained by the following: 1) this discrepancy may be because of the limited sample size. The previous meta-analysis included only 9 articles (2047 cases and 2040 controls) in Caucasians, whereas we included 11 articles (3069 cases and 6584 controls); 2) we excluded the studies that do not follow HWE. Therefore, the results of this study are more reliable than the previous meta-analysis; 3) The sensitivity analysis was conducted through two methods in this meta-analysis, and the results were consistent with the previous results, suggesting the results of this study were stable.

Although the mechanism was not clear, we assumed that the mechanism underlying the cancer risk was related to the levels of p50. In recent studies $[16,68]$, it was shown that the probable mechanism of the observed association may be relative to the upregulation of the expression and activity of p50, once p50 is over expressed, it may influence cancer risk. However, cancer is a complex disease influenced by genetic and other non-genetic factors such as environment, lifestyle and habits that might influence the incidence ratio of cancer[64-66]. The NFKB1 -94ins/del ATTG promoter polymorphism was just one of susceptibility genes, and all these non-genetic factors could influence the expression of the gene. Therefore, the differences in this NFKB1 polymorphism in Asians and Caucasians may result from different genetic background, environment, lifestyle or other factors.

According to the results of the analysis of the relationship between the NFKB1 -94ins/del ATTG promoter polymorphism and subtypes of cancer, the NFKB1 -94ins/del ATTG promoter polymorphism is a risk factor for oral squamous cell carcinoma, ovarian cancer and nasopharyngeal carcinoma. This result suggests that the NFKB1 gene might have some relevance in these cancers. The inconsistent may be caused by their different micro-environment, because the same genetic factor might have different correlations in different cancer site [67]. Our study has a relatively small number of cases in each cancer type, which might create significant or insignificant associations by chance due to insufficient statistical power. Therefore, further research should enlarge the sample for each cancer type and validate the cancer-specificity effect of this functional polymorphism on cancer susceptibility.
This study has several limitations, like any metaanalysis. First, moderate heterogeneity was detected in some comparisons and may distort the meta-analysis. Second, the non-genetic risk factors such as environment are also important in the incidence ratio of cancer. Unfortunately, there were not enough data for further subgroup analysis; therefore, the results of subgroup analysis may affect the validity of the conclusions. Third, in the subgroup analysis, we found that our analysis was limited to Asian and Caucasian populations, so we do not know whether these conclusions can also be adopted in other populations. This may cause publication bias. Finally, the sample sizes for each type of cancer were relatively small, so further research should enlarge the sample sizes to obtain more accurate conclusions.

Despite these limitations, our study has several strengths. First, all of the studies that we chose agreed with HWE, which may increase the validity of the conclusions. Second, the sample size of our study was more than double that of the previous meta-analysis, significantly increasing the statistical power. Although this updated meta-analysis had the above-mentioned shortcomings, we tried to control them through perfected searching, sifting the good ones from the bad and performing the statistical analyses strictly.

\section{CONCLUSIONS}

We conclude that the NFKB1 -94ins/del ATTG promoter polymorphism is associated with cancer risk not only in Asian populations, but also in Caucasian populations. Moreover, there might be a significant association with increased susceptibility between the NFKB1 -94ins/del ATTG promoter polymorphism and ovarian cancer, oral squamous cell carcinoma, and nasopharyngeal carcinoma. Well-designed studies with larger representative sample sizes are necessary to confirm our results.

\section{MATERIALS AND METHODS}

The systematic review and meta-analysis was in accordance with the PRISMA (Preferred Reporting Items for Systematic Reviews and Meta-Analyses) guidelines

\section{Publication search}

A systematic search of the PubMed, Web of Science, Science Direct, Ovid, China National Knowledge Infrastructure $(\mathrm{CNKI})$ and Wan fang Data electronic databases was performed with the following key words: ("polymorphisms" OR "polymorphism" OR "SNP" OR "single nucleotide polymorphism" OR "variant" OR "mutation") AND ("neoplasm" OR "cancer" OR "tumor"

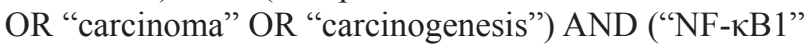


OR "Nuclear factor- $\kappa \mathrm{B} 1$ " OR "Nuclear factor $\kappa \mathrm{B} 1$ " OR "NFKB1" OR "nuclear factor kappa B1" OR "NF kappa B1” OR “nuclear factor kB1” OR “rs28362491”).

\section{Inclusion criteria}

No language or other restrictions were imposed in this study and the inclusion criteria were as follows: 1) case-control design; 2) studies evaluating the association between the NFKB1 -94ins/del ATTG promoter polymorphism and cancer risk; 3) studies describing the genotype distributions in detail to calculate the OR and 95\% CI in cases and controls; and 4) the distribution data in controls must be consistent with Hardy-Weinberg Equilibrium (HWE).

\section{Exclusion criteria}

The exclusion criteria in this meta-analysis were as follows: 1) not concerned with cancer risk; 2) only a case population; 3) duplication of a previous publication; 4) the control group does not conform to HWE; and 5) animal studies.

\section{Data extraction}

According to the criteria listed above, information was carefully extracted from eligible studies independently by each investigator (Y.Q.L. and D.W.). The following information was collected from each study: surname of the first author, year of publication, ethnicity of subjects, genotyping method, frequencies of the genotypes in cases and controls, cancer type. The different ethnicities were categorized as Caucasian or Asian. Studies that investigated more than one type of cancer were regarded as individual datasets only in subgroup analyses according to cancer type. Any discrepancy was resolved through discussion.

\section{Statistical analysis}

The strength of association between the NFKB1 -94ins/del ATTG promoter polymorphism and cancer was estimated through OR with $95 \%$ CI. The combined ORs were determined by the $\mathrm{Z}$ test, and a $P$ value of $<0.05$ was considered to be statistically significant. The NFKB1 -94ins/del ATTG promoter polymorphism consists of three genotypes: homozygote insertion or wild-type (II), homozygote deletion or variant (DD), and heterozygous ins/del (ID). We measured the association based on five different genetic models: the dominant (II+ID vs. DD), recessive (II vs. ID + DD), homozygote (II vs. DD), heterozygote (ID vs. DD), and allele (I vs. D) models. To investigate the origin of heterogeneity, subgroup analyses based on ethnicity (Caucasian and Asian) and cancer type were performed to identify the association between the NFKB1 -94ins/del ATTG promoter polymorphism and cancer susceptibility.

We used the $Q$ and $I^{2}$ statistical tests to check the statistical heterogeneity among studies. If the $P$ value was $<0.05$ and $I^{2} \geq 50 \%$ indicating heterogeneity, then a random-effect model was chosen to calculate the pooled OR; otherwise, a fixed-effect model was selected [12]. A sensitivity analysis was conducted by sequentially excluding each study to evaluate the stability of the results. The publication bias was estimated by Egger's test and Begg's funnel plots, with potential publication bias if $p<0.05$ and the plot was asymmetrical [13]. The statistical analyses were performed using STATA 11.0 software (Stata Corp, College Station, TX, USA).

\section{CONFLICT OF INTERESTS}

Authors declare no financial disclosure or conflicts of interest. .

\section{REFERENCES}

1. Pharoah PD, Dunning AM, Ponder BA. Association studies for finding cancer-susceptibility genetic variants. Nature Reviews Cancer. 2004; 4:850-860.

2. Foulkes WD. Inherited susceptibility to common cancers. New England Journal of Medicine. 2008; 359:2143-2153.

3. Sun XF, Zhang H. NFKB and NFKBI polymorphisms in relation to susceptibility of tumour and other diseases. Histology \& Histopathology. 2007; 22:1387-1398.

4. Sen R, Baltimore D. Multiple nuclear factors interact with the immunoglobulin enhancer sequences.Cell. 1986; 46:705-716.

5. Sen R, Baltimore D. Inducibility of kappa immunoglobulin enhancer-binding protein Nf-kappa B by a posttranslational mechanism. Cell. 1986; 47:921-928.

6. Mathew S, Murty VV, Dallafavera R. Chromosomal localization of genes encoding the transcription factors, c-rel, NF-kappa Bp50, NF-kappa Bp65, and lyt-10 by fluorescence in situ hybridization. Oncogene. 1993; 8:191193.

7. Yu Y, Wan Y, Huang C. The biological functions of NFkappaB1 (p50) and its potential as an anti-cancer target. Current Cancer Drug Targets. 2009; 9:566-571.

8. Karban AS, Okazaki T, Panhuysen CI, Gallegos T, Potter JJ, Bailey-Wilson JE, Silverberg MS, Duerr RH, Cho JH, Gregersen PK, Wu Y, Achkar JP, Dassopoulos T, et al. Functional annotation of a novel NFKB1 promoter polymorphism that increases risk for ulcerative colitis. Human Molecular Genetics. 2004; 13:35-45.

9. Kopp TI, Andersen V, Tjonneland A. Polymorphisms in 
NFKB1 and TLR4 and interaction with dietary and life style factors in relation to colorectal cancer in a Danish prospective case-cohort study. Plos One. 2015, 10(2).

10. Meredith S. Genetic variation in innate immunity and inflammation pathways associated with lung cancer risk. Cancer. 2012; 119:5630-5636.

11. Cheng $\mathrm{CW}, \mathrm{Su}$ JL, Lin CW. Effects of NFKB1 and NFKBIA Gene Polymorphisms on Hepatocellular Carcinoma Susceptibility and Clinicopathological Features. Plos One. 2013; 8:e56130.

12. Cochran WG. The comparison of percentages in matched samples. Biometrika. 1950; 37:256-266.

13. Schnee S, Enoch M, Noriega-Crespo A. Bias in metaanalysis detected by a simple, graphical test. BMJ. 1997; 315: 629-634.

14. Lin SC, Liu CJ, Yeh WI. Functional polymorphism in NFKB1 promoter is related to the risks of oral squamous cell carcinoma occurring on older male areca (betel) chewers. Cancer Letters. 2006; 243:47-54.

15. Riemann K, Becker L, Struwe H, Nückel H, Dührsen U, Alakus H, Winde G, Neuhäuser M, Rübben H, Schmitz KJ, Wohlschlaeger J, Schmid KW and Siffert W. No association of the NFKB1 insertion/deletion promoter polymorphism with survival in colorectal and renal cell carcinoma as well as disease progression in B-cell chronic lymphocytic leukemia. Pharmacogenetics \& Genomics. 2006; 16:783788.

16. Riemann K, Becker L, Struwe H. Insertion/deletion polymorphism in the promoter of NFKB1 as a potential molecular marker for the risk of recurrence in superficial bladder cancer. International Journal of Clinical Pharmacology \& Therapeutics. 2007; 45:423-430.

17. He Y, Zhang H, Yin J. IkappaBalpha gene promoter polymorphisms are associated with hepatocarcinogenesis in patients infected with hepatitis B virus genotype C. Carcinogenesis. 2009; 30: 1916-1922.

18. Lo SS, Chen JH, Wu CW. Functional polymorphism of NFKB1 promoter may correlate to the susceptibility of gastric cancer in aged patients. Surgery. 2009; 145:280-285.

19. Zhang P, Wei Q, Li X. A functional insertion/deletion polymorphism in the promoter region of the NFKB1 gene increases susceptibility for prostate cancer. Cancer Genetics \& Cytogenetics. 2009; 191:73-77.

20. Zhou B, Rao L, Li Y. A functional insertion/deletion polymorphism in the promoter region of NFKB1 gene increases susceptibility for nasopharyngeal carcinoma. Cancer Letters. 2008; 275:72-76.

21. Andersen V, Christensen J, Overvad K. Polymorphisms in NFkB, PXR, LXR, and risk of colorectal cancer in a prospective study of Danes. Bmc Cancer. 2010; 10:282293.

22. Tang TL, Cui S, Deng XZ. Insertion/deletion polymorphism in the promoter region of NFKB1 gene increases susceptibility for superficial bladder cancer in Chinese.
DNA \& Cell Biology. 2010; 29:9-12.

23. Zhou B, Qie M, Wang Y. Relationship between NFKB1 -94 insertion/deletion ATTG polymorphism and susceptibility of cervical squamous cell carcinoma risk. Annals of Oncology. 2010; 21:506-511.

24. Fan Y, Yu W, Ye P. NFKB1 insertion/deletion promoter polymorphism increases the risk of advanced ovarian cancer in a Chinese population. DNA \& Cell Biology. 2011; 30:241-245.

25. Song S, Chen D, Lu J. NFkB1 and NFkBIA Polymorphisms Are Associated with Increased Risk for Sporadic Colorectal Cancer in a Southern Chinese Population. Plos One. 2011; 6: e21726.

26. Lin $\mathrm{CW}$, Hsieh $\mathrm{YS}$, Hsin $\mathrm{CH}$. Effects of NFKB1 and NFKBIA gene polymorphisms on susceptibility to environmental factors and the clinicopathologic development of oral cancer. Plos One. 2012; 7: e35078.

27. Ungerbäck J, Belenki D, Ulhassan A J. Genetic variation and alterations of genes involved in NFKB/TNFAIP3and NLRP3-inflammasome signaling affect susceptibility and outcome of colorectal cancer. Carcinogenesis. 2012; 33:2126-2134.

28. Vangsted AJ, Nielsen KR, Klausen TW. A functional polymorphism in the promoter region of the IL1B, gene is associated with risk of multiple myeloma. British Journal of Haematology. 2012; 158:515-518.

29. Cheng $\mathrm{CW}, \mathrm{Su}$ JL, Lin CW. Effects of NFKB1 and NFKBIA Gene Polymorphisms on Hepatocellular Carcinoma Susceptibility and Clinicopathological Features. Plos One. 2013; 8:e56130.

30. Huo. Roles of functional NFKB1 and beta-TrCP insertion/ deletion polymorphisms; in mRNA expression and epithelial ovarian cancer susceptibility. Genetics \& Molecular Research. 2013; 12:3435-3443.

31. Kopp TI, Friis S, Christensen J. Polymorphisms in genes related to inflammation, NSAID use, and the risk of prostate cancer among Danish men. Cancer Genetics. 2013; 206:266-278..

32. Li P, Gu J, Yang X. Functional promoter-94 ins/del ATTG polymorphism in NFKB1 gene is associated with bladder cancer risk in a Chinese population. Plos One. 2014;8: e71604.

33. Hua T, Qinsheng W, Xuxia W. Nuclear Factor-Kappa B1 is Associated With Gastric Cancer in a Chinese Population. Medicine. 2014; 93:e279-e279.

34. Oltulu YM, Coskunpinar E, Ozkan G. Investigation of NFkappa B1 and NF- kappa BIA Gene Polymorphism in NonSmall Cell Lung Cancer. Biomed Res Int. 2014.2014.

35. Zhang Q, Ji XW, Hou XM. Effect of functional nuclear factor-kappaB genetic polymorphisms on hepatitis B virus persistence and their interactions with viral mutations on the risk of hepatocellular carcinoma. Annals of Oncology. 2014; 25:2413-2419. 
36. Chen LP, Cai PS, Liang HB. Association of the genetic polymorphisms of NFKB1 with susceptibility to ovarian cancer. Genetics \& Molecular Research. 2015; 14:82738282.

37. Han X, Zhang JJ, Yao N. Polymorphisms in NFKB1 and NFKBIA Genes Modulate the Risk of Developing Prostate Cancer among Han Chinese. Medical Science Monitor. 2014; 21:1707-1715.

38. Kopp TI, Andersen V, Tjonneland A. Polymorphisms in NFKB1 and TLR4 and interaction with dietary and life style factors in relation to colorectal cancer in a Danish prospective case-cohort study. Plos One. 2015; 10(2).

39. Li X, Gao Y, Zhou H. The relationship between functional

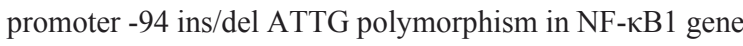
and the risk of urinary cancer. Cancer Biomarkers. 2015; 16:41-49.

40. Li X, Zhang C, Qiao W. NFKB1 -94ins/del ATTG polymorphism increases osteosarcoma risk in a Chinese Han population. International Journal of Clinical \& Experimental Medicine. 2014; 8:1420-1423.

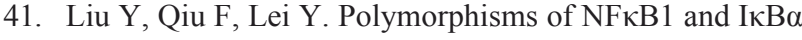
and Their Synergistic Effect on Nasopharyngeal Carcinoma Susceptibility. Biomed Research International. 2015; 2015.

42. $\mathrm{Lu} \mathrm{ZH,} \mathrm{Gu} \mathrm{XJ,} \mathrm{Shi} \mathrm{KZ.} \mathrm{Association} \mathrm{between} \mathrm{genetic}$ polymorphisms of inflammatory response genes and the risk of ovarian cancer. Journal of the Formosan Medical Association. 2015; 115:31-37.

43. Wang X, Peng H, Liang Y. A functional insertion/deletion polymorphism in the promoter region of the NFKB1 gene increases the risk of papillary thyroid carcinoma. Genetic Testing \& Molecular Biomarkers. 2015; 19:167-171.

44. Wang Y, Chen L, Pan L. The association between NFKB194ins/del ATTG polymorphism and non-small cell lung cancer risk in a Chinese Han population. International Journal of Clinical \& Experimental Medicine. 2015; 8:8153-157.

45. Duan W, Wang E, Zhang F. Association Between the NFKB1-94ins/del ATTG Polymorphism and Cancer Risk: An Updated Meta-Analysis. Cancer Investigation.2014; 32: 311-320.

46. Nian X, Zhang W, Li L. Meta-analysis of studies on the association between the NF- $\mathrm{BB} 1-94$ ins/del ATTG promoter polymorphism and cancer. Tumour Biology. 2014; 35:11921-11931.

47. Yang X, Li P, Tao J. Association between NFKB1 -94ins/del ATTG Promoter Polymorphism and Cancer Susceptibility: An Updated Meta-Analysis. International Journal of Plant Genomics. 2014; 2014:1013-1030.

48. Zou YF, Yuan FL, Feng XL. Association Between NFKB1 -94ins/delATTG Promoter Polymorphism and Cancer Risk: A Meta-Analysis. Cancer Investigation. 2010; 29:78-85.

49. Chen F, Castranova V, Shi X. New insights into the role of nuclear factor-kappaB, a ubiquitous transcription factor in the initiation of diseases. Clinical Chemistry. 1999; 45:7-17.
50. Yehua Liu, Jiachun Lu; The association between the genetic variants in NFKB1 and NFKBIA and risk of Nasopharyngeal Carcinoma. Dissertation. 2012.

51. Rybka J, Gebura, K., Wrobel, T. Variations in genes involved in regulation of the nuclear factor-kB pathway and the risk of acute myeloid leukaemia. International Journal of Immunogenetics. 2016; 43:101-106.

52. Burnik FS, Yalçin S. NFKB1 -94 insertion/deletion ATTG polymorphism in gastroenteropancreatic neuroendocrine tumors. Meeting Abstracts of the Physical Society of Japan, 2009; 55:381-385.

53. Cai H, Sun L, Cui L. A functional insertion/deletion polymorphism (-94 ins/del ATTG) in the promoter region of the NFKB1 gene is related to the risk of renal cell carcinoma. Urologia Internationalis. 2013; 91:206-212.

54. Huang D, Yang L, Liu Y. Functional polymorphisms in $\mathrm{NF} \kappa \mathrm{B} 1 / \mathrm{I} \kappa \mathrm{B} \alpha$ predict risks of chronic obstructive pulmonary disease and lung cancer in Chinese. Human genetics. 2013; 132: 451-460.

55. Suzairi MSM, Tan SC, Aizat AAA. The functional -94 insertion/deletion ATTG polymorphism in the promoter region of NFKB1 gene increases the risk of sporadic colorectal cancer. Cancer Epidemiology. 2013; 37:634-638.

56. Wang Z, Liu Q L, Sun W. Genetic polymorphisms in inflammatory response genes and their associations with breast cancer risk. Croatian Medical Journal. 2014; 55:638646.

57. Pallavi S, Anoop K, Showket H. NFKB1/NFKBIa polymorphisms are associated with the progression of cervical carcinoma in HPV-infected postmenopausal women from rural area. Tumor Biology. 2015; 36:62656276.

58. Escobar GF, Arraes JA, Bakos L. Polymorphisms in CYP19A1 and NFKB1 genes are associated with cutaneous melanoma risk in southern Brazilian patients. Melanoma Research. 2016.

59. Lewander A, Butchi AK, Gao J. Polymorphism in the promoter region of the NFKB1 gene increases the risk of sporadic colorectal cancer in Swedish but not in Chinese populations. Scandinavian Journal of Gastroenterology. 2009; 42:1332-1338.

60. Bu H, Rosdahl I, Sun XF. Importance of polymorphisms in NF-kappaB1 and NF-kappaBIalpha genes for melanoma risk, clinicopathological features and tumor progression in Swedish melanoma patients. Journal of Cancer Research \& Clinical Oncology. 2007; 133:859-866.

61. Li X, Gao Y, Zhou H. The relationship between functional promoter -94 ins/del ATTG polymorphism in NF-KB1 gene and the risk of urinary cancer. Cancer Biomarkers. 2015; 16:41-49.

62. Huang D, Yang L, Liu Y. Functional polymorphisms in $\mathrm{NF} \kappa \mathrm{B} 1 / \mathrm{I} \kappa \mathrm{B} \alpha$ predict risks of chronic obstructive pulmonary disease and lung cancer in Chinese. Human genetics. 2013; 132: 451-460. 
63. Yin J, Wang H, Vogel U. Association and interaction of NFKB1, rs28362491 insertion/deletion ATTG polymorphism and PPP1R13L, and CD3EAP, related to lung cancer risk in a Chinese population. Tumor Biology. 2015:1-7.

64. Andersen V, Holst R, Kopp TI, Tjønneland A, Vogel U. Interactions between diet, lifestyle and IL10, IL1B, and PTGS2/COX-2 gene polymorphisms in relation to risk of colorectal cancer in a prospective Danish case-cohort study. PLoS One. 2013;8:e78366.

65. Carolyn M. Hutter, Leah E. Mechanic, Nilanjan Chatterjee. Gene-Environment Interactions in Cancer Epidemiology: A National Cancer Institute Think Tank Report. Genetic Epidemiology. 2013; 37:643-657.

66. Taniar D, Gervasi O, Murgante B. Identification of gene-environment interactions in cancer studies using penalization. Genomics. 2013; 102:189-94.
67. Saidak,Z, Mentaverri,RBrown,EM. The role of the calciumsensing receptor in the development and progression of cancer. Endocrine Reviews. 2009; 30:178-195.

68. Karban AS, Okazaki T, Panhuysen CI, Gallegos T, Potter JJ, Bailey-Wilson JE, Silverberg MS, Duerr RH, Cho JH, Gregersen PK, Wu Y, Achkar JP, Dassopoulos T, Mezey E, Bayless TM, Nouvet FJ and Brant SR. Functional annotation of a novel NFKB1 promoter polymorphism that increases risk for ulcerative colitis. Human Molecular Genetics. 2004; 13:35-45. 